\title{
Oral L-cysteine ethyl ester (LCEE) reduces amoebic gill disease (AGD) in Atlantic salmon Salmo salar
}

\author{
Shane D. Roberts ${ }^{1,2,3, *}$, Mark D. Powell ${ }^{1,2}$ \\ ${ }^{1}$ School of Aquaculture, Tasmanian Aquaculture and Fisheries Institute, University of Tasmania, Locked Bag 1370, \\ Launceston, Tasmania 7250, Australia \\ ${ }^{2}$ Cooperative Research Centre for Sustainable Aquaculture of Finfish, PO Box 120, Henley Beach, South Australia 5022, \\ Australia \\ ${ }^{3}$ Present address: South Australian Research and Development Institute, Aquatic Sciences, PO Box 120, Henley Beach, \\ South Australia 5022, Australia
}

\begin{abstract}
There is a need for the development of alternative therapeutic treatments for amoebic gill disease (AGD) in Atlantic salmon Salmo salar L. to maintain the sustainability of the Tasmanian Atlantic salmon aquaculture industry. This study aimed to assess the effects of the mucolytic drug L-cysteine ethyl ester (LCEE) on marine Atlantic salmon mucus and whether or not it may have a therapeutic advantage for the alleviation of AGD when administered orally. We also aimed to document any physiological consequences of LCEE. Results showed that LCEE significantly decreased the viscosity of marine Atlantic salmon mucus both in vitro, where LCEE concentration showed a negative relationship to mucus viscosity $\left(\mathrm{R}^{2}=0.95\right.$ at $\left.11.5 \mathrm{~s}^{-1}\right)$, and in vivo. Oral administration of LCEE at $52.7 \mathrm{mg}$ LCEE $\mathrm{kg}^{-1}$ fish $\mathrm{d}^{-1}$ over $2 \mathrm{wk}$ significantly delayed the progression of AGDassociated pathology during an aggressive, cohabitation induced, laboratory infection. Medicated fish had approximately $50 \%$ less gill filaments affected by AGD than control fed fish at $3 \mathrm{~d}$ postinfection when assessed using histology. Palatability of medicated feed was shown to be approximately $65 \%$ of control feed. No osmoregulatory disturbance was seen in medicated fish, although blood and whole body flux data indicated a slight acidosis coinciding with an increased plasma total ammonia concentration. However, both variables were within a tolerable physiological range and returned to control levels $3 \mathrm{~d}$ post-cessation of medicated feed. LCEE holds potential as an in-feed additive when administered over 2 wk prior to infection to delay the progression of AGD associated pathology. From the parameters measured, LCEE seems to have minimal physiological consequences after 2 wk of administration.
\end{abstract}

KEY WORDS: Fish gill disease $\cdot$ Salmonid $\cdot$ In-feed treatment $\cdot$ Oral therapeutant $\cdot$ Mucolytic drug Mucus viscosity $\cdot$ Physiological effects

Resale or republication not permitted without written consent of the publisher

\section{INTRODUCTION}

Outbreaks of amoebic gill disease (AGD) in Tasmanian farmed Atlantic salmon Salmo salar L. are a significant health problem affecting this commercial aquaculture industry (see Munday et al. 2001, Nowak et al. 2002). The current commercial treatment for AGD is freshwater bathing whole pens of fish (Parsons et al. 2001), preferably in water from a soft freshwater source (Roberts \& Powell 2003b). Recently, we found that water hardness $\left(\mathrm{mg} \mathrm{l}^{-1} \mathrm{CaCO}_{3}\right)$ is a limiting factor for the efficacy of freshwater bathing (Roberts \& Powell 2003b). Although an improvement to this treatment has been identified, it is still an expensive, time consuming and labour intensive method. Thus, there is a need for the identification and development of alternative therapeutic treatments and/or treatment regimes.

Gill pathology of AGD-affected fish involves epithelial hyperplasia, as well as mucous cell hyperplasia and an extensive mucus secretion (Munday et al. 1990, Nowak \& Munday 1994, Zilberg \& Munday 2000, 
Roberts \& Powell 2003a). It has been previously suggested that excessive branchial mucus impairs $\mathrm{CO}_{2}$ excretion, leading to respiratory acidosis and subsequent death in AGD affected fish (Powell et al. 2000). The break-up and removal of mucus from the gills seems to be an important function of freshwater bathing as a treatment (Munday et al. 2001). Indeed, freshwater bathing has been shown to significantly decrease mucus viscosity of marine Atlantic salmon (Roberts 2004). Thinner and more removable mucus is thought to aid the significant lesion fragmentation and shedding of AGD lesion-associated hyperplastic gill tissue, as well as sloughing of gill-associated amoebae in soft, freshwater-bathed fish (Roberts \& Powell 2003b).

Therapeutic mucolytic drugs have been extensively used for the alleviation of respiratory diseases associated with excessive production and accumulation of mucus in humans and domestic animals. N-acetylcysteine (NAC) is a widely used mucolytic agent that by virtue of its free sulfhydryl group reacts with and ruptures the disulfide bridges of mucoproteins leading to a decreased mucus viscosity (Walters et al. 1985, Holdiness 1991, Houtmeyers et al. 1999). The NAC analogue, L-cysteine ethyl ester (LCEE), was successfully tested as an in-feed additive to protect coho salmon Oncorhynchus kisutch against the harmful phytoplankter Chaetoceros concavicornis (Yang \& Albright 1994). C. Concavicornis is a harmful marine diatom that irritates the gills of fish leading to excessive mucus production and accumulation, and subsequent mortality (Yang \& Albright 1992). LCEE has apparently been tested as an in-feed mucolytic additive for AGD-affected Atlantic salmon without success (as stated by Munday et al. 2001), although no experimental design, method, or actual results were given.

The aim of this study was to firstly assess whether LCEE actively reduces the viscosity of marine Atlantic salmon mucus, in vitro, and at what concentrations. The mucus layer between salmonid species has been shown to significantly differ, and may hold implications for treatments that target the mucus layer (Roberts \& Powell 2005a,b). We also aimed to assess whether or not pre-feeding LCEE to marine Atlantic salmon retards the development of pathological gill lesions characteristic of AGD. In this study we use counts of histological AGD lesions as the measure of pathology. The presence of histological AGD lesions forms the case definition for this disease (B. Nowak pers. comm.). In laboratory infections it is comparable to gross pathology, the commercial monitoring tool used in Tasmania (Zilberg et al. 2001, Adams et al. 2004). We also aimed to document any physiological disturbances in fish medicated with LCEE.

\section{MATERIALS AND METHODS}

Fish. Atlantic salmon Salmo salar were obtained from Springfield hatchery (Springfield Fisheries, Springfield, Tasmania) as freshwater-adapted fish and maintained in $4000 \mathrm{l}$ closed recirculating freshwater systems, each consisting of a fiberglass Rathburn tank connected to a biofilter, at $15^{\circ} \mathrm{C}$. Freshwater $\mathrm{pH}$ and total ammonia were maintained at 6.9 to 7.2 and $<0.25 \mathrm{mg} \mathrm{l}^{-1}$ respectively. Prior to experimentation, fish were acclimated to $32 \% 1 \mu \mathrm{m}$ filtered seawater over $7 \mathrm{~d}$ and maintained in closed recirculating systems of the same design with the addition of a foam fractionator. Seawater $\mathrm{pH}$ range, total ammonia and temperature were maintained at 7.7 to $8.2,<0.25 \mathrm{mg} \mathrm{l}^{-1}$ and $15^{\circ} \mathrm{C}$ respectively. During non-experimental periods, fish were fed to satiation daily with commercial salmon pellets (Skretting).

Experimental protocol. In vitro effect of LCEE on mucus: Cutaneous mucus was non-lethally collected (see 'Mucus collection and viscosity'), and stored at $-80^{\circ} \mathrm{C}$, from sea-caged Atlantic salmon, (Huon Aquaculture) of mean mass $( \pm \mathrm{SE}) 1.80 \pm 0.15 \mathrm{~kg}$, lightly anaesthetised with clove oil $(0.005 \%)$. These fish had been in seawater (30 to 35\%) for more than 6 mo and did not exhibit any clinical signs of AGD, although they had a history of AGD infection and subsequent freshwater bathing treatments.

Mucus samples were thawed at room temperature, briefly vortexed and centrifuged at $10000 \times g$ for $5 \mathrm{~min}$. The supernatant was collected and used for the in vitro trial of LCEE. Two ml samples of mucus supernatant had $20 \mu$ of either deionised water $\left(\mathrm{dH}_{2} \mathrm{O}\right)$ (control) or LCEE stock solution added to achieve final concentrations of $0,8,12,100$ and $200 \mu \mathrm{g}$ LCEE ml ${ }^{-1}$ mucus (ppm). For each concentration of LCEE a control was run at the same time. Treatment solutions, replicated 3 times, were incubated in a water bath at $17^{\circ} \mathrm{C}$ for $2 \mathrm{~h}$. The viscosity of solutions was subsequently measured (see 'Mucus collection and viscosity'). This procedure was staggered so that solutions could be immediately measured after their $2 \mathrm{~h}$ incubation time.

In vivo trial of $L C E E$ as an in-feed additive: Seawater-acclimated Atlantic salmon, AGD-naïve, of mean mass $( \pm$ SE) $0.30 \pm 0.01 \mathrm{~kg}$ and mean condition index $( \pm \mathrm{SE}) \quad 0.84 \pm 0.01$ were randomly allocated to two 40001 Rathburn tanks (73 fish each) for the medication phase of this experiment. One group was fed LCEE treated salmon pellets and the other control salmon pellets (see 'Medicated and control feed') over 2 wk. Fish were lethally sampled pre and post the 2 wk medicated feed period. This type of experimental design, using 1 tank per feeding treatment during an initial medication phase has been used before by Stone et al. (2000). After the 2 wk medica- 
tion period, 6 fish from each treatment were transferred to individual flux boxes to measure net $\left[\mathrm{H}^{+}\right]$ and total ammonia fluxes (see 'Whole body ionic flux'). A further 15 fish from each treatment were marked intra-dermally on the ventral surface with saturated alcian blue dye using a Panjet injector (Hart \& Pitcher 1969) to allow discrimination between treatment groups, and transferred to a single established infection tank for AGD challenge by cohabitation (Roberts \& Powell 2005a,b). Briefly, AGD had been maintained in this tank for several months, with introduced fish exhibiting gross signs of AGD within $3 \mathrm{~d}$ of cohabitation. The presence of Neoparamoeba pemaquidensis, the putative agent of AGD, was routinely confirmed using a modified indirect fluorescent antibody test (Roberts \& Powell 2003b), PCR (Wong et al. 2004), immunohistochemistry (Bridle et al. 2003) and by visually identifying parasomes within isolated gill amoebae (Morrison et al. 2004). All fish were fed to satiation daily with non-medicated pellets, and further lethally sampled 3 and $5 \mathrm{~d}$ into their cohabitation with AGD-affected fish. Lethal sampling in this experiment $(\mathrm{n}=42)$ entailed anaesthetising fish with clove oil (0.02\%) and subsequently collecting cutaneous mucus (see 'Mucus collection and viscosity'), blood and gills. Fish were bled from the caudal vessels using a heparinised syringe (lithium heparin $100 \mathrm{IU} \mathrm{ml}^{-1}$, Sigma) and the blood immediately measured for its $\mathrm{pH}$ (see 'Plasma and water analysis'). Blood was subsequently centrifuged at $10000 \times g$ for $90 \mathrm{~s}$ and the plasma immediately refrigerated $\left(4^{\circ} \mathrm{C}\right)$ then frozen at $-20^{\circ} \mathrm{C}$ for further analysis (see 'Plasma and water analysis'). The second left gill arch was excised and fixed in Davidson's seawater fixative for at least $72 \mathrm{~h}$, then transferred to $70 \%$ ethanol for storage and later histological examination. Gill samples were processed, stained with haematoxylin and eosin (H\&E) and their pathology quantified (per cent of gill filaments with an AGD lesion) according to the methods of Roberts \& Powell (2003a).

Medicated and control feed. Medicated feed was prepared by coating commercial salmon pellets with an LCEE and cod liver oil suspension such that the final concentration was $8 \mathrm{~g} \mathrm{LCEE} \mathrm{kg}^{-1}$ pellets. This was achieved by dissolving $8 \mathrm{~g}$ LCEE (LCEE hydrochloride,

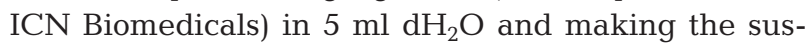
pension up to $20 \mathrm{ml}$ with cod liver oil. The suspension was then emulsified by vigorous shaking and evenly coated, by mixing, onto $1 \mathrm{~kg}$ of pellets. Control feed was $20 \mathrm{ml}$ of 1:1 $\mathrm{dH}_{2} \mathrm{O}$ :cod liver oil suspension emulsified and coated onto $1 \mathrm{~kg}$ of pellets. Medicated and control pellets were made daily and stored at $4{ }^{\circ} \mathrm{C}$. Fish were fed twice daily by hand to determine the point of satiation so as to achieve a maximum dosage with the medicated feed and a recording of palatability for both treatments. Satiation was defined as greater than 2 pellets settling on the bottom of the tank uneaten. Daily feed consumption was measured in each tank by counting the number of uneaten pellets and subtracting the weight from the weight of pellets fed to the tank. Over the 2 wk medicated feeding period, a daily mean $( \pm \mathrm{SE})$ dose of $52.7 \pm 3.5 \mathrm{mg}$ LCEE kg ${ }^{-1}$ fish $^{-1}$ was achieved.

Mucus collection and viscosity. Cutaneous mucus was collected and its viscosity measured as per the protocol of Roberts \& Powell (2005a,b). Briefly, mucus was collected by gently scraping the back of a sterile scalpel blade over the body in a head-to-tail direction, avoiding the anal area. Viscosity was measured in 1 $\mathrm{ml}$ aliquots with a cone-plate viscometer (cone angle of $1.565^{\circ}$, model LVT-C/P 42, Brookfield Engineering Laboratories) connected to a circulating water bath (Thermoline) set at $17.0 \pm 0.1^{\circ} \mathrm{C}$. Sample and water viscosities were measured over a range of shear rates $\left(11.5,23,46\right.$ and $\left.115 \mathrm{~s}^{-1}\right)$. In vitro treatment viscosity measurements are documented as a proportion of control mucus viscosity. In vivo viscosity measurements are documented in respect to the viscosity of water. The viscosity of water is 1 centipoise at $20^{\circ} \mathrm{C}$ and only slightly dependant on temperature (Withers 1992).

Whole body ionic flux. Control $(n=6)$ and LCEE $(\mathrm{n}=6)$ fed marine Atlantic salmon, AGD-naïve, were placed in individual closed black acrylic boxes to determine whole body $\left[\mathrm{H}^{+}\right]$and total ammonia fluxes. Each fish was lightly anaesthetized with $0.005 \%$ clove oil before being placed in a flux box with flowing recirculating seawater $(32 \%$, $\mathrm{pH}$ range $=7.9$ to 8.0 , total ammonia $<0.25 \mathrm{mg} \mathrm{l}^{-1}$ and $15^{\circ} \mathrm{C}$ ) at a flow rate of $2.9 \mathrm{l}$ $\min ^{-1}$ (air-saturated). Following a $24 \mathrm{~h}$ recovery period, water flow to each flux box was stopped and fish were exposed to static seawater (air-saturated by continuous bubbling) for $3 \mathrm{~h}$. Water $\mathrm{pH}$ was measured at time 0,1 , 2 and $3 \mathrm{~h}$, and water samples were collected at time 0 and $3 \mathrm{~h}$ and immediately frozen at $-20^{\circ} \mathrm{C}$ for later total ammonia analysis. All fish were weighed and the flux box water volume measured. Flux rates were calculated as:

$$
\frac{\left(\left([x]_{t_{0}}-[x]_{t_{1}}\right) \times V\right)}{W t \times T}
$$

Where $[x]_{t_{0}}$ is the concentration of the measured variable at time $0,[x]_{t_{1}}$ is the concentration at time $1, V$ is the volume (l) of water in the flux box, $W t$ is the weight of the fish $(\mathrm{kg})$ and $T$ is the time interval between $t_{0}$ and $t_{1}(\mathrm{~h})$.

Plasma and water analysis. Blood plasma osmolality was measured using a $\mathrm{VAPRO}^{\circledR}$ vapor pressure osmometer (model 5520, WESCOR ${ }^{\circledR}$ ). Total plasma 
protein concentrations were determined using a commercially available assay kit (Sigma). Total plasma and water ammonia concentrations were determined using the salicylate-hypochlorite method of Verdouw et al. (1978). Plasma and water $\mathrm{pH}$ were measured using a TPS 900-P pH-mV-temperature meter and Hanna (HI 1330) electrode.
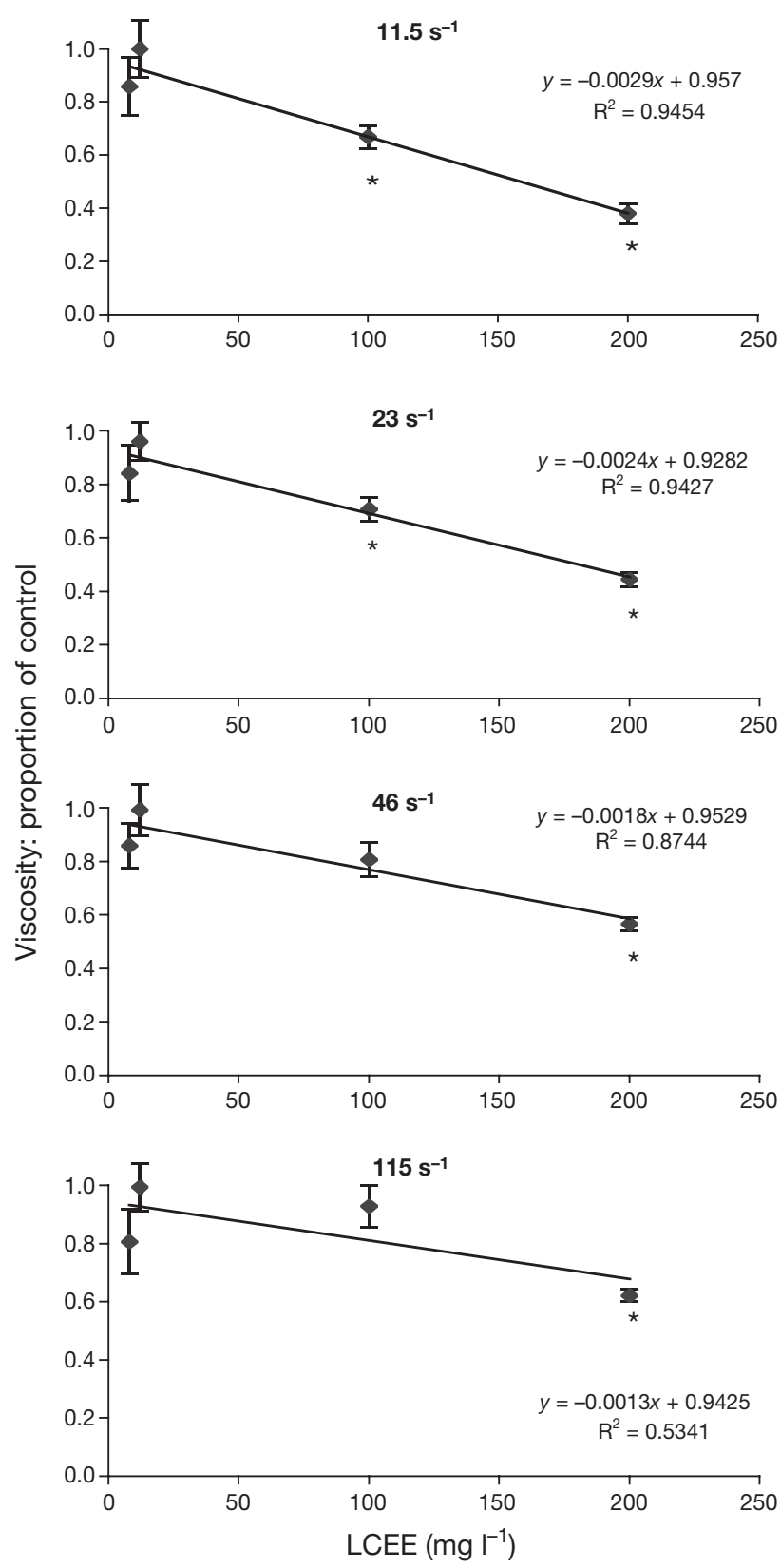

Fig. 1. Salmo salar. Viscosity, as a proportion of controls, of marine Atlantic salmon mucus incubated with L-cysteine ethyl ester (LCEE) over $2 \mathrm{~h}$ at $17^{\circ} \mathrm{C}$ for 4 concentrations $(8,12,100$ and $\left.200 \mathrm{mg} \mathrm{l}^{-1}\right)$ in vitro (mean $\left.\pm \mathrm{SE}\right)(\mathrm{n}=26)$. Note that the effect of LCEE differs between shear rates $\left(11.5,23,46\right.$ and $\left.115 \mathrm{~s}^{-1}\right)$. Asterisks indicate significant differences from controls $\left({ }^{*} \mathrm{p}<0.05\right)$

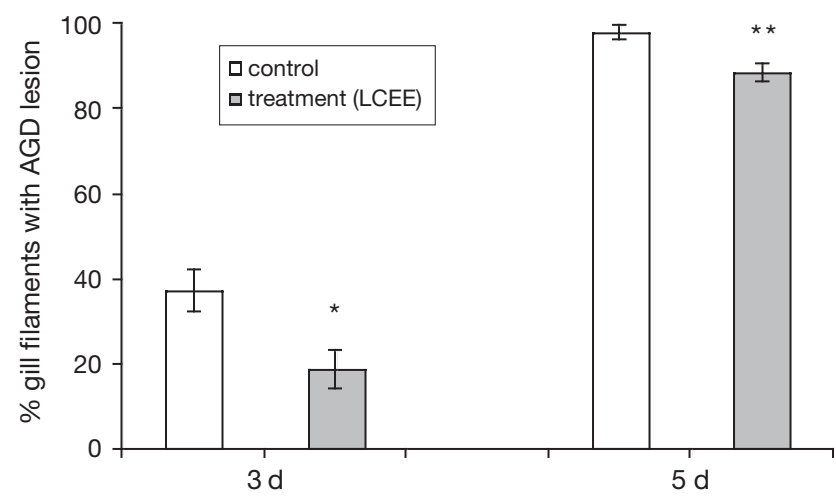

Fig. 2. Salmo salar. Percent of gill filaments with an amoebic gill disease (AGD) lesion during an aggressive laboratory infection, induced by cohabitation, 3 and $5 \mathrm{~d}$ post-cessation of medication. Data represent mean \pm SE for control and LCEEtreated Atlantic salmon $(n=23)$. Asterisks indicate significant differences from controls $\left({ }^{*} \mathrm{p}<0.05,{ }^{*} \mathrm{p}<0.01\right)$

Statistical analysis. Net total ammonia flux and $\mathrm{pH}$ data were analysed using repeated measures ANOVA and 2-tailed $t$-tests were employed to compare individual means to a hypothesized mean of zero. All other data were analysed using either a 1- or 2-way ANOVA, and where necessary followed by a Student-NewmanKeuls post-hoc test to identify statistical differences among treatment means. For 2-way ANOVAs that identified a significant interaction as well as a significant difference among treatments, both independent variables were grouped together for the post-hoc test. Homoscedasticity and normality of the data were checked by both Levene's test and by visually assessing residual plots. Where necessary, square root $(n+1)$ and $\log _{10}(n+10)$ transformations of data were employed to ensure homogeneity. In all cases, significance was accepted for $\mathrm{p}<0.05$. Data analysis and statistical testing were performed using SPSS 11.5 software (SPSS). Values are given as mean \pm standard error (SE).

\section{RESULTS}

\section{In vitro effect of LCEE on mucus}

Mucus viscosity significantly decreased with increasing concentration of LCEE for each shear rate $\left(F_{3,25}=33.21, \mathrm{p}<0.001\right.$ at $\left.11.5 \mathrm{~s}^{-1}\right)$ (Fig. 1). However, the greatest effect of LCEE was seen at the lower shear rates, where viscosity significantly decreased compared to controls $\left(F_{1,25}=17.15, \mathrm{p}<0.001\right.$ at $\left.11.5 \mathrm{~s}^{-1}\right)$ at 100 and $200 \mathrm{mg} \mathrm{l}^{-1}$ LCEE. The slope of the linear regression for viscosity and LCEE concentration also decreased due to increased shear rate $(-0.0029$ at 
$11.5 \mathrm{~s}^{-1}$ compared to -0.0013 at $115 \mathrm{~s}^{-1}$ ), illustrating the greater effect of LCEE at lower shear rates. The negative relationship that viscosity has with LCEE concentration was best explained at $11.5 \mathrm{~s}^{-1}\left(\mathrm{R}^{2}=0.95\right)$ compared to $115 \mathrm{~s}^{-1}\left(\mathrm{R}^{2}=0.53\right)$ (Fig. 1).

\section{In vivo trial of LCEE as an in-feed additive}

Pathology (\% gill filaments with an AGD lesion) was significantly delayed in LCEE-treated fish compared to controls $\left(F_{1,22}=16.42, \mathrm{p}<0.001\right)$, and significantly increased in both groups over the $5 \mathrm{~d}$ infection period $\left(F_{1,22}=348.85, \mathrm{p}<0.001\right.$, Fig. 2$)$.

Palatability of medicated feed was approximately $65 \%$ of, and significantly less than, control feed $\left(F_{1,27}=\right.$ 10.05, $\mathrm{p}<0.01$, Fig. 3). In addition, only the control fish showed a significantly higher condition index post 2 wk feed period compared to the pre-feeding period $\left(0.97 \pm 0.02\right.$ and $0.84 \pm 0.01$ respectively, $F_{2,44}=6.15$, $\mathrm{p}<0.01$ ). No significant difference was seen between pre- and post-feeding weights for either treatment group.

Cutaneous mucus viscosity was significantly lower in LCEE-treated fish compared to controls at all shear rates $\left(F_{1,10}=15.1, \mathrm{p}<0.01\right.$ at $11.5 \mathrm{~s}^{-1}$, Fig. 4$)$. Viscosity showed shear dependent behaviour, typical of nonNewtonian fluids, where viscosity decreased with an increase in shear rate. The greatest difference between treatments was seen at the lowest shear rate $\left(11.5 \mathrm{~s}^{-1}\right)$.

Net acid $\left(\mathrm{H}^{+}\right)$fluxes for both treatments were positive over a $3 \mathrm{~h}$ period, indicating whole body net acid uptake (Fig. 5). The mean $(\mu)$ cumulative net flux for

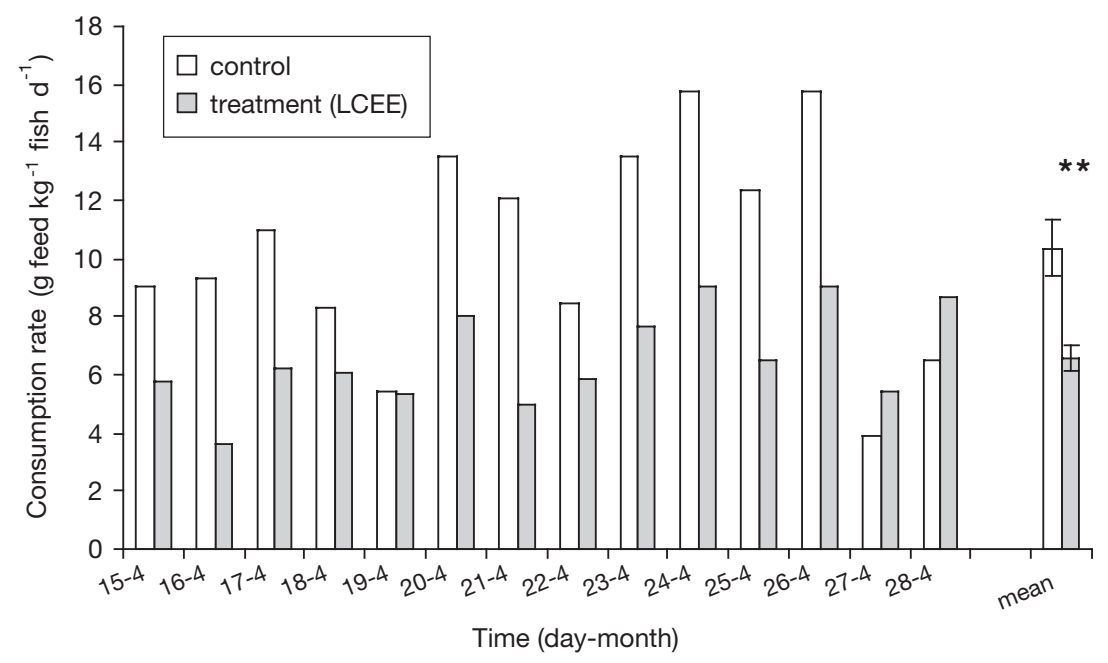

Fig. 3. Salmo salar. Palatability of control and LCEE coated salmon feed for marine Atlantic salmon. Data represent mean \pm SE daily consumption rate and cumulative mean for a $2 \mathrm{wk}$ experimental feeding period $\left(\mathrm{g} \mathrm{kg}^{-1}\right.$ fish $\left.\mathrm{d}^{-1}\right)(\mathrm{n}=$ 28). Asterisks indicate a significant difference between treatments $(* * p<0.01)$

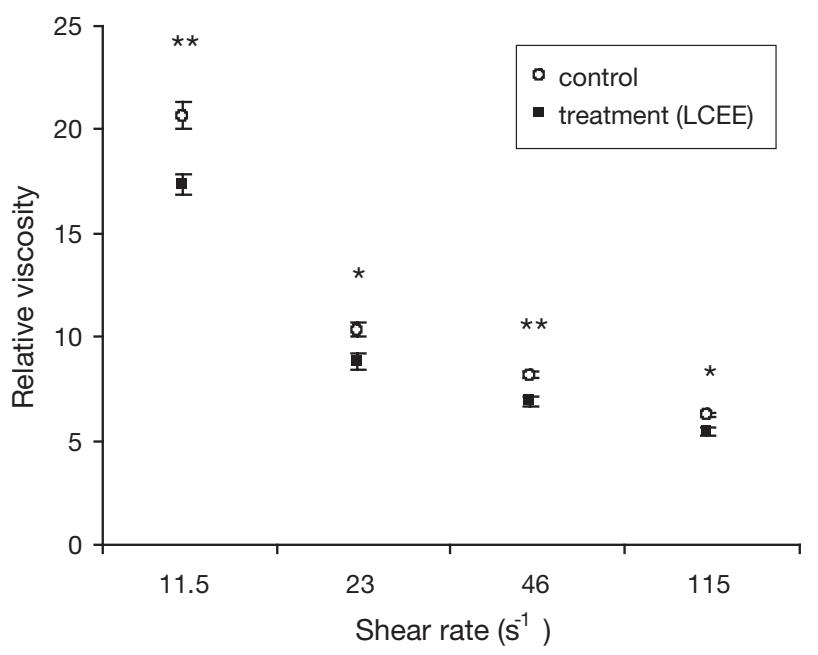

Fig. 4. Salmo salar. Relative viscosity of mucus (with respect to water) for marine Atlantic salmon after a $2 \mathrm{wk}$ experimental feeding period of control and LCEE coated pellets (mean \pm $\mathrm{SE})(\mathrm{n}=11)$. Note that the viscosity of mucus is dependent on shear rate. Asterisks indicate significant differences between treatments $(* \mathrm{p}<0.05, * * \mathrm{p}<0.01)$

LCEE-treated fish only was significantly positive $(\mu \neq 0$, $\mathrm{p}<0.05)$. However, both control and LCEE-treated fish had significant positive net fluxes at 2 and $3 \mathrm{~h}(\mu \neq 0$, $\mathrm{p}<0.05)$. A significant difference between treatments $\left(F_{1,10}=5.79, \mathrm{p}<0.05\right)$ and over time $\left(F_{2,20}=3.74, \mathrm{p}<\right.$ $0.05)$ was found.

Net total ammonia fluxes over $3 \mathrm{~h}$ for both treatments were significantly negative, indicating significant whole body net total ammonia effluxes $(\mu \neq 0, p<$ 0.05, Fig. 6). However, no significant difference was found between control and LCEEtreated fish $\left(F_{1,11}=4.38, \mathrm{p}=0.06\right)$.

Caudal blood $\mathrm{pH}$ post 2 wk feed period was significantly lower in LCEE-treated fish compared to controls $\left(F_{1,11}=10.86, \mathrm{p}<0.01\right.$, Table 1$)$. However, $3 \mathrm{~d}$ after medicated feeding ceased, no significant difference was found between treatments.

Plasma total ammonia significantly differed between treatments $\left(F_{1,47}=\right.$ 4.17, $\mathrm{p}<0.05)$ and over time $\left(F_{3,47}=\right.$ 3.68, $\mathrm{p}<0.05$, Table 1). Post $2 \mathrm{wk}$ feed period, LCEE-treated fish had a significantly higher plasma total ammonia concentration than controls ( $p<0.05)$. However, $3 \mathrm{~d}$ after medicated feeding ceased, no significant difference was found between treatments.

No significant difference was found between treatments for plasma protein or osmolality ( $p>0.05$, Table 1$)$. 


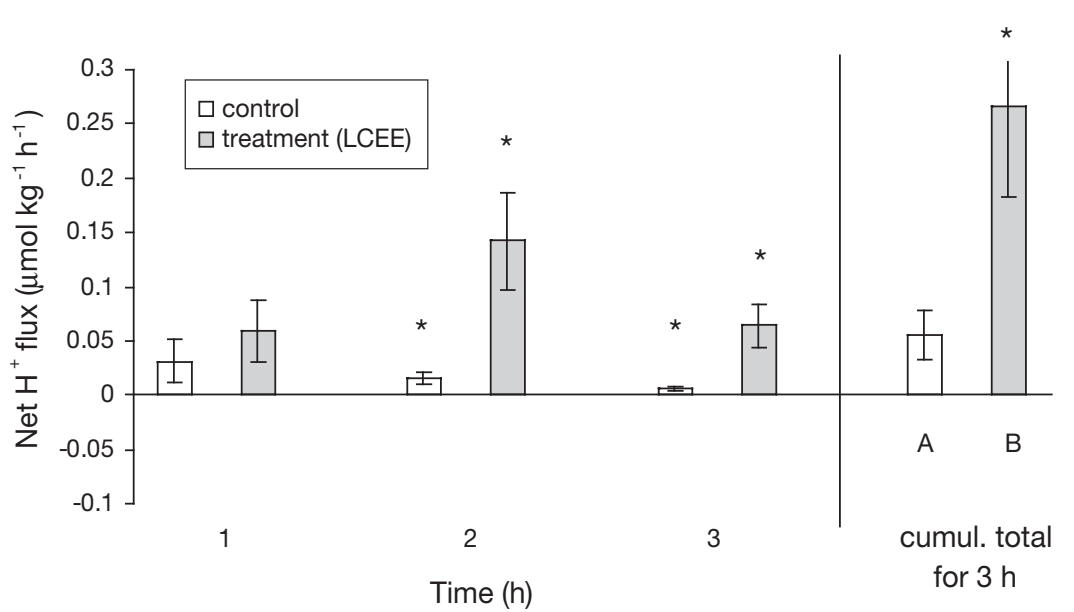

Fig. 5. Salmo salar. Whole body net acid $\left(\mathrm{H}^{+}\right)$flux over a $3 \mathrm{~h}$ period, and cumulative total for that period, in control and LCEE-treated Atlantic salmon post 2 wk experimental feeding (mean $\pm S E)(n=12)$. Letters indicate significant differences between treatment means $(\mathrm{p}<0.05)$. Asterisks indicate means that are significantly different from a hypothetical mean $(\mu)$ of $0(\mu \neq 0, p<0.05)$

tion, medicated fish had approximately $50 \%$ less gill filaments affected by histological AGD lesions compared to control fish $(18.5 \%$ compared to $37.3 \%$ of gill filaments affected by AGD respectively). A significant difference between treatments in such an aggressive laboratory infection holds significant potential for the use of LCEE in slower, less extreme infections typical of field outbreaks of AGD. Comparatively, field outbreaks of clinical AGD on commercial salmon farms exhibit much less severe infection rates than laboratory-induced infections. Roberts \& Powell (2003b) showed that AGD-affected fish in a field experiment on a commercial salmon farm had $5 \%$ of gill filaments with an AGD lesion, which coincided with a gross gill score that initiated

\section{DISCUSSION}

In vitro, marine Atlantic salmon mucus was shown to significantly decrease in viscosity at 100 and $200 \mathrm{mg} \mathrm{l}^{-1}$ LCEE after $2 \mathrm{~h}$, where viscosity had a negative linear relationship to LCEE concentration. Also, the greatest difference in viscosity was seen at the lowest shear rates. Previously, we also found that in salmonid mucus the greatest differences in viscosity between treatments were seen at the lowest shear rate, $11.5 \mathrm{~s}^{-1}$ (Roberts \& Powell 2005a,b). In vivo, after oral administration of LCEE over 2 wk at $52.7 \mathrm{mg} \mathrm{LCEE} \mathrm{kg}{ }^{-1}$ fish $\mathrm{d}^{-1}$, marine Atlantic salmon mucus viscosity significantly decreased compared to controls. NAC and its analogue L-cysteine have both been previously shown to significantly reduce the viscosity of human nasal mucus in vitro by $31 \%$ of controls (Sheffner 1963). Since Sheffner (1963) measured viscosity at $37^{\circ} \mathrm{C}$ and shear rate was not mentioned, direct comparisons of the results between studies cannot be made. NAC, along with other cysteine compounds including LCEE, possess a free sulfhydryl group that reacts with and ruptures the disulfide bridges of mucoproteins leading to a decreased mucus viscosity (Walters et al. 1985, Holdiness 1991, Houtmeyers et al. 1999). When ingested by humans and canines, NAC has also been shown to decrease the production and secretion of mucus by mucous cells (Aylward et al. 1980, Martin et al. 1980). This has been proposed to be a result of increased glutathione synthesis (Cotgreave et al. 1987).

Subsequent to oral administration of LCEE over $2 \mathrm{wk}$ at $52.7 \mathrm{mg}$ LCEE $\mathrm{kg}^{-1}$ fish $\mathrm{d}^{-1}$, AGD pathology was significantly delayed compared to control fish during an aggressive laboratory infection. After $3 \mathrm{~d}$ post-infec- freshwater bathing. Fish returned to a similar level of infection 8 wk post-bath. Also, Adams \& Nowak (2003) found AGD-affected fish from a commercial salmon farm to have 10 to $20 \%$ of gill filaments with an AGD lesion 18 wk after first being introduced to estuarine/ marine sites from freshwater. Differences in infection rates between laboratory and field situations occur due to optimal conditions for AGD in the laboratory, where no freshwater bathing treatment is administered, and there is the potential for continuous infection of gills under laboratory conditions because water is recirculated.

Yang \& Albright (1994) previously found that LCEE protected coho salmon Oncorhynchus kisutch against the harmful phytoplankter Chaetoceros concavicornis,

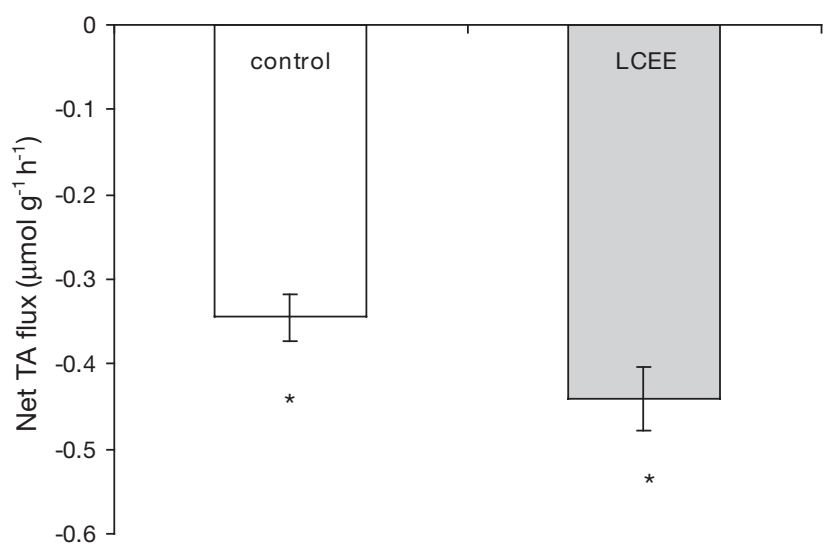

Fig. 6. Salmo salar. Whole body net total ammonia (TA) flux during a $3 \mathrm{~h}$ period in control and LCEE-treated Atlantic salmon post $2 \mathrm{wk}$ experimental feeding (mean $\pm \mathrm{SE})(\mathrm{n}=12)$. Asterisks indicate means that are significantly different from a hypothetical mean $(\mu)$ of $0(\mu \neq 0, p<0.05)$ 
Table 1. Salmo salar. Caudal blood $\mathrm{pH}(\mathrm{n}=12)$, plasma total ammonia $(\mathrm{TA})(\mathrm{n}=$ $48)$, plasma protein $(\mathrm{n}=48)$, and plasma osmolality $(\mathrm{n}=48)$ for control and LCEE-treated Atlantic salmon post 2 wk experimental feeding and during AGD challenge. Values are means \pm SE. Asterisks indicate means significantly different between treatments; ${ }^{*} \mathrm{p}<0.05,{ }^{* *} \mathrm{p}<0.01$

\begin{tabular}{|c|c|c|c|c|c|c|}
\hline \multirow{3}{*}{$\begin{array}{l}\text { Caudal blood } \\
\text { parameter }\end{array}$} & & & \multirow{2}{*}{\multicolumn{2}{|c|}{$\begin{array}{l}\text { - Treatment } \\
\text { AGD }(3 \mathrm{~d})\end{array}$}} & \multirow{2}{*}{\multicolumn{2}{|c|}{$\operatorname{AGD}(5 \mathrm{~d})$}} \\
\hline & \multicolumn{2}{|c|}{ Post feed } & & & & \\
\hline & Control & LCEE & Control & LCEE & \multicolumn{2}{|c|}{ Control LCEE } \\
\hline $\mathrm{pH}$ & $\begin{array}{l}7.09 \\
(0.01)\end{array}$ & $\begin{array}{c}7.03 \\
(0.02)^{* *}\end{array}$ & $\begin{array}{c}7.15 \\
(0.02)\end{array}$ & $\begin{array}{l}7.16 \\
(0.01)\end{array}$ & - & - \\
\hline $\mathrm{TA}\left(\mu \mathrm{mol} \mathrm{l}^{-1}\right)$ & $\begin{array}{c}93.9 \\
(15.6)\end{array}$ & $\begin{array}{c}177.4 \\
(16.8)^{*}\end{array}$ & $\begin{array}{l}102.9 \\
(9.4)\end{array}$ & $\begin{array}{l}91.6 \\
(6.8)\end{array}$ & $\begin{array}{l}122.2 \\
(10.5)\end{array}$ & $\begin{array}{c}117.1 \\
(6.1)\end{array}$ \\
\hline Protein $\left(\mathrm{g} \mathrm{l}^{-1}\right)$ & $\begin{array}{l}39.1 \\
(2.1)\end{array}$ & $\begin{array}{l}39.3 \\
(2.1)\end{array}$ & $\begin{array}{l}33.3 \\
(1.6)\end{array}$ & $\begin{array}{l}36.7 \\
(1.4)\end{array}$ & $\begin{array}{l}42.1 \\
(3.2)\end{array}$ & $\begin{array}{l}43.6 \\
(3.6)\end{array}$ \\
\hline $\begin{array}{l}\text { Osmolality } \\
\left(\mathrm{mOsmol} \mathrm{kg}^{-1}\right)\end{array}$ & $\begin{array}{l}338.8 \\
(3.1)\end{array}$ & $\begin{array}{c}344.1 \\
(5.2)\end{array}$ & $\begin{array}{c}345.3 \\
(3.6)\end{array}$ & $\begin{array}{c}349.5 \\
(4.8)\end{array}$ & $\begin{array}{c}350.0 \\
(3.5)\end{array}$ & $\begin{array}{c}349.3 \\
(3.2)\end{array}$ \\
\hline
\end{tabular}

possibly by the lower mucus viscosity, which was more easily washed off the primary and secondary lamellae. Indeed, in this study we found that LCEE significantly reduced Atlantic salmon mucus viscosity and significantly delayed the progression of AGD pathology. Reducing the viscosity of the protective mucus barrier of the host fish possibly reduced the attachment of amoebae, thereby reducing the subsequent infection rate. However, it cannot be ruled out that LCEE possibly induces other changes to the mucus layer, such as an altered mucus composition, leading to a less favourable environment for amoebae attachment and subsequent pathology. Previously, it was shown that LCEE does not possess any amoebastatic or amoebocidal properties at the in vivo concentration used in this study (Roberts 2004).

Palatability, measured as mean consumption rate, of medicated feed over 2 wk was approximately $65 \%$ of control feed. Consequently, control fish only significantly increased in condition index, although marginally, over the experimental period. The difference in consumption rate was assumed not to significantly affect blood and whole body flux measures, or the AGD infection since the last $2 \mathrm{~d}$ of feeding prior to infection were similar for both groups. Yang \& Albright (1994) tested LCEE as an in-feed additive for coho salmon Oncorhynchus kisutch because it was apparently odorless compared to other mucolytic cysteine compounds. Reactive NAC, a molecule analogous to LCEE, decomposes to acetate and cysteine with liberation of hydrogen sulfide (Ziment 1978). During our experiments, it was noted that when LCEE was mixed in with commercial salmon pellets, an obnoxious egg smell, characteristic of hydrogen sulfide, emanated from the coated feed. This indicated a high reactivity of LCEE to the pellets. The smell was exacerbated when we initially attempted to mix LCEE in with gelatine to coat the pellets. It was for these reasons that we used cod liver oil to coat LCEE onto pellets and medicated feed was made daily to limit decomposition of LCEE.

No significant differences were seen in plasma protein and osmolality concentrations, suggesting no acute osmoregulatory disturbance in LCEE treated fish. However, blood $\mathrm{pH}$ and net acid $\left(\mathrm{H}^{+}\right)$whole body fluxes indicated that LCEE treated fish were slightly acidotic compared to controls. The net acid uptake seen in control fish has similarly been documented before in Atlantic salmon (Roberts \& Powell 2003a) and rainbow trout (Powell \& Perry 1998). Our values for net acid uptake in control fish $\left(0.05 \mu \mathrm{mol} \mathrm{kg} \mathrm{k}^{-1} \mathrm{~h}^{-1}\right)$ are similar to control fish in Roberts \& Powell (2003a) $\left(0.14 \mu \mathrm{mol} \mathrm{kg} \mathrm{kg}^{-1} \mathrm{~h}^{-1}\right.$. In this study, we documented a difference between treatments in caudal blood $\mathrm{pH}$ of 0.06. For a comparative value, Powell et al. (2000) documented the difference in arterial blood $\mathrm{pH}$ between AGD-affected and unaffected fish to be between 1.5 and 2.0. Also, plasma total ammonia concentrations were elevated (to $0.177 \mathrm{mmol} \mathrm{l}^{-1}$ ) in LCEE-treated fish after 2 wk of medication. Plasma total ammonia in teleost fish varies between 0.05 and $1 \mathrm{mmol} \mathrm{l}^{-1}$ before toxicity starts to occur at $2 \mathrm{mmol} \mathrm{l}^{-1}$ (Wright 1995). However, $3 \mathrm{~d}$ after the cessation of medicated feeding, blood $\mathrm{pH}$ and plasma total ammonia showed a return in LCEE-treated fish to control levels. One of the known metabolites of NAC is cysteic acid (Holdiness 1991), which along with the increased plasma ammonium, could possibly be a cause of a decreased blood $\mathrm{pH}$ in salmon that are fed LCEE. The breakdown of mucoproteins by LCEE would be expected to lead to an increase in ammonia since this is the main end product of protein metabolism in teleost fish (Wright 1995). A previous study by Holdiness (1991) found that when NAC was administered orally to humans biochemical and haematological effects were observed but were not clinically relevant.

LCEE holds potential as an in-feed mucolytic drug for the delay of AGD pathology when administered over $2 \mathrm{wk}$ at approximately $50 \mathrm{mg}$ LCEE kg ${ }^{-1}$ fish d $^{-1}$ prior to infection. From the physiological parameters measured, LCEE seems to have minor physiological consequences for medicated fish. The slight acidosis and elevated plasma total ammonia concentrations in medicated fish were within a tolerable physiological range and were alleviated within $3 \mathrm{~d}$ of cessation of medication. 
Acknowledgements. We would like to thank Huon Aquaculture Pty Ltd for the donation of fish for non-lethal sampling of mucus. We would also like to thank the Atlantic salmon aquaculture industry for the supply of fish for laboratory experiments and Mr. M. Attard for fish maintenance. Our thanks also to Dr. S. Nicol, Department of Anatomy and Physiology, University of Tasmania, for the loan of the cone-plate viscometer, and to Dr. B. Nowak for reviewing the manuscript. This work formed part of a project of Aquafin CRC, and received funds from the Australian Government's CRC Program, the Fisheries R\&D Corporation and other CRC participants.

\section{LITERATURE CITED}

Adams MB, Nowak BF (2003) Amoebic gill disease: sequential pathology in cultured Atlantic salmon, Salmo salar L. J Fish Dis 26:601-614

Adams MB, Ellard K, Nowak BF (2004) Gross pathology and its relationship with histopathology of amoebic gill disease (AGD) in farmed Atlantic salmon, Salmo salar L. J Fish Dis 27:1-11

Aylward M, Maddock J, Dewland P (1980) Clinical evaluation of acetylcysteine in the treatment of patients with chronic obstructive bronchitis: a balanced double-blind trial with placebo control. Eur J Respir Dis 61(Suppl 111):81-89

Bridle A, Butler R, Nowak BF (2003) Immunostimulatory CpG oligodeoxynucelotides increase resistance against amoebic gill disease in Atlantic salmon, Salmo salar L. J Fish Dis 26:367-371

Cotgreave IA, Eklund A, Larsson K, Moldeus PW (1987) No penetration of orally administered $\mathrm{N}$-acetyl-cysteine into bronchoalveolar lavage fluid. Eur J Respir Dis 70:73-77

Hart PJB, Pitcher TJ (1969) Field trials of fish marking using a jet inoculator. J Fish Biol 1:383-385

Holdiness MR (1991) Clinical pharmacokinetics of N-acetylcysteine. Clin Pharmacokinet 20(2):123-134

Houtmeyers E, Gosselink R, Gayan-Ramirez G, Decramer M (1999) Effects of drugs on mucus clearance. Eur Respir J 14:452-467

Martin R, Mitchell L, Marriott C (1980) The effect of mucolytic agents on the rheological and transport properties of canine tracheal mucus. Am Rev Respir Dis 121:495-500

Morrison RN, Crosbie PBB, Nowak BF (2004) The induction of laboratory based amoebic gill disease (AGD) revisited. J Fish Dis 27:445-449

Munday BL, Foster CK, Roubal FR, Lester RJG (1990) Paramoebic gill infection and associated pathology of Atlantic salmon, Salmo salar, and rainbow trout, Salmo gairdneri, in Tasmania. In: Cheng FO, Cheng TC (eds) Pathology in marine science. Academic Press, San Diego, CA, p 215-222

Munday BL, Zilberg D, Findlay V (2001) Gill disease of marine fish caused by infection with Neoparamoeba pemaquidensis. J Fish Dis 24:497-507

Nowak BF, Munday BL (1994) Histology of the gills of Atlantic salmon during the first few months following transfer to sea water. Bull Eur Assoc Fish Pathol 14:77-81

Nowak BF, Carson J, Powell MD, Dykova I (2002) Amoebic Gill Disease in the marine environment. Bull Eur Assoc Fish Pathol 22(2):144-147

Parsons H, Nowak B, Fisk D, Powell M (2001) Effectiveness of commercial freshwater bathing as a treatment against amoebic gill disease in Atlantic salmon. Aquaculture 195: 205-210
Powell MD, Perry SF (1998) Acid-base and ionic fluxes in rainbow trout (Oncorhynchus mykiss) during exposure to chloramine-T. Aquat Toxicol 43:13-24

Powell MD, Fisk D, Nowak BF (2000) Effects of graded hypoxia on Atlantic salmon infected with amoebic gill disease. J Fish Biol 57:1047-1057

Roberts SD (2004) Improving the treatment of amoebic gill disease in salmonids with soft freshwater and the mucolytic drug L-cysteine ethyl ester. PhD thesis, University of Tasmania, Launceston

Roberts SD, Powell MD (2003a) Comparative ionic flux and gill mucous cell histochemistry: effects of salinity and disease status in Atlantic salmon (Salmo salar L.). Comp Biochem Physiol 134(A):525-537

Roberts SD, Powell MD (2003b) Reduced total hardness of fresh water enhances the efficacy of bathing as a treatment for amoebic gill disease in Atlantic salmon, Salmo salar L. J Fish Dis 26:591-599

Roberts SD, Powell MD (2005a) The viscosity and glycoprotein biochemistry of salmonid mucus varies with species, salinity and the presence of amoebic gill disease. J Comp Physiol B 175:1-11

Roberts SD, Powell MD (2005b) Erratum. The viscosity and glycoprotein biochemistry of salmonid mucus varies with species, salinity and the presence of amoebic gill disease. J Comp Physiol B 175:219

Sheffner AL (1963) The reduction in vitro in viscosity of mucoprotein solutions by a new mucolytic agent, N-acetyl-Lcysteine. Ann N Y Acad Sci 106:298-310

Stone J, Sutherland IH, Sommerville C, Richards RH, Endris RG (2000) The duration of efficacy following oral treatment with emamectin benzoate against infestations of sea lice, Lepeophtheirus salmonis (Kroyer), in Atlantic salmon Salmo salar L. J Fish Dis 23:185-192

Verdouw H, van Etcheld CJA, Dekkers EM (1978) Ammonia determination based on indophenol formation with sodium salicylate. Water Res 12:399-402

Walters CR, Marriott C, Turner RJ (1985) The use of SEM to evaluate the effects of mucolytic agents on mucus gel structure. J Pharm Pharmacol 37:143-152

Withers PC (1992) Comparative animal physiology. Saunders College Publishing, Orlando, FL

Wong FYK, Carson J, Elliott NG (2004) 18S ribosomal DNAbased PCR identification of Neoparamoeba pemaquidensis, the agent of amoebic gill disease in sea-farmed salmonids. Dis Aquat Org 60:65-76

Wright PA (1995) Nitrogen excretion: three end products, many physiological roles. J Exp Biol 198:273-281

Yang CZ, Albright LJ (1992) Effects of the harmful diatom, Chaetoceros concavicornis on respiration of rainbow trout Oncorhynchus mykiss. Dis Aquat Org 14:105-114

Yang CZ, Albright LJ (1994) Anti-phytoplankton therapy of finfish: the mucolytic agent L-cysteine ethyl ester protects coho salmon Oncorhynchus kisutch against the harmful phytoplankter Chaetoceros concavicornais. Dis Aquat Org 20:197-202

Zilberg D, Munday BL (2000) Pathology of experimental amoebic gill disease in Atlantic salmon, Salmo salar L., and the effect of pre-maintenance of fish in sea water on the infection. J Fish Dis 23:401-407

Zilberg D, Gross A, Munday BL (2001) production of salmonid amoebic gill disease by exposure to Paramoeba sp. harvested from the gills of infected fish. J Fish Dis 24: 79-82

Ziment TL (1978) Respiratory pharmacology and therapeutics. Saunders, Philadelphia, PA

Proofs received from author(s): July 20, 2005 